\title{
Language and Literacy of Deaf Children
}

\section{Dr. Abdulaziz Abdullah Alothman}

Associate Professor of Special Education

Majmaah University, School of Education, Department of Special Education. aa.alothman@ mu.edu.sa

\begin{abstract}
Children with deafness encounter multiple problems in the course of developing their language and literacy skills. A detailed review of the literature on issues affecting deaf children in acquiring language and literacy skills is presented in this study. Many problems pertaining to the development of literacy skills and the interrelationship between reading and writing are demonstrated. A review was carried out across six scientific databases. The articles were categorised to address issues pertaining to the development of language and literacy skills, with a focus on reading and writing. The review helped demonstrate important factors affecting the development of language skills among children with deafness, and highlighted the need for different approaches to respond to them.
\end{abstract}

Keywords:

Deaf children, language, literacy skills, Hearing loss, Writing and reading.

Article Received: 18 August 2020, Revised: 3 November 2020, Accepted: 24 November 2020

\section{Introduction}

Deafness has various influences on children's development and attainments in terms of their language skills. Issues pertaining to the development of language and literacy skills are significant and sensitive areas for deaf children, as deafness may hinder their language attainment and development. Spoken language is not always accessible to deaf children. Sign language is not always readily available to deaf children either as over $90 \%$ deaf children are born to parents who can both hear, and do not already have knowledge of sign language (Mitchell \& Karchmer, 2004). Consequently, many deaf children experience a marked delay in language comprehension and this has adverse effects on the development of their literacy and language (Golos \& Moses, 2013; Moeller et al., 2010). The development of these skills among deaf children is a critical issue for deaf educators as well ( Golos \& Moses, 2013).

Problems with language may subsist despite early identification and intervention (Goberis et al., 2012). Language development for deaf children has been examined from different perspectives in the literature. Developmental issues are usually affected by several factors. Such as age, degree of hearing loss, presence of other disabilities, socio-economic backgrounds, and communication among the family (Fulcher et al., 2012; Kushalnagar et al., 2010; Shojaei et al., 2016). Studies have found that early language access is a major solution to literacy challenges and can help plug gaps in literacy skills among deaf children (Freel et al., 2011; Myers et al., 2010).

This study aims to review the literature on the development of language and literacy skills among deaf children. This paper examines issues in language development, particularly reading and writing skills, and investigates factors that influence language development among deaf children. This review also provides useful insights on the strengths and weaknesses of deaf children with respect to language development, particularly reading and writing, in order to benefit special education teachers and parents in framing their approaches.

\subsection{Research Questions}


This review aims to overcome language development issues encountered in the course of reading and writing and to investigate factors such as age, degree of deafness, age of student at the time of deafness, use of hearing aids, and the children's family and socio-economic backgrounds, all of which influence the language development of deaf children. This study asks three research questions on the effect of deafness on language development:

1. What are the strengths and weaknesses of deaf children with respect to the use of language while reading and writing?

2. What factors influence deaf children in their language development while reading and writing? What is the degree of such influence?

3. What are the approaches and models relied on in addressing deaf children's language acquisition, as well as in teaching language?

The analysis that followed pinpointed the emergence of three themes: (a) addressing the effect of deafness on language development, (b) literacy of deaf children, and (c) factors influencing language development.

\section{Methods}

The literature review comprised four phases: search, selection, literature description, and analysis of findings. In the first phase, studies were identified through international databases such as PubMed, Semantic scholar, and JSTOR using the following keywords: 'language and deaf,' 'writing and deaf,' 'reading and deaf,' and 'literacy and deaf.' In the first round, words targeting skills (i.e. 'reading,' and 'writing ') were used. A large number of publications were found after this. Next, this was narrowed down using 'deaf children' as the target phrase. In the second phase, studies reporting on development levels pertaining to the reading and/or writing skills of deaf children were identified. After reading abstracts in the first phase, studies that focused on the reading and/or writing skills among deaf children were selected. Studies that examined the direct effects of popular educational approaches (e.g. auditory-oral, total communication, bilingual) were also selected. Studies that did not fulfil the criteria were omitted. In the third phase, the articles were read and analysed in full, to describe the themes mentioned above.

Table 1 presents the frequency of publications.

There were numerous papers from a single journal.

\begin{tabular}{|l|l|}
\hline Name of database & Numbers of articles \\
\hline JSTOR & 24 \\
\hline Semantic scholar & 31 \\
\hline PubMed & 38 \\
\hline SAGE Journals & 4 \\
\hline
\end{tabular}

\section{The Effect of Deafness on Language Development}

The ability to understand and develop language is very important for deaf children to discover the world around them. For most children, the linguistic intake or receptiveness is possible through the auditory channel. This is not the case with deaf children. Despite the use of several means of communication such as sign language, finger spelling, and written language, a deaf child cannot develop complete linguistic intake or input (Alothman, 2014; Herman et al., 2014). Liberman (2014) mentioned that the visual perception of language as used by deaf children differs from auditory perception. For example, speech reading as a visual stimulus provides limited information and written language differs from spoken language; many elements present in speech cannot be represented in writing, such as rhythm and duration (Griffin, 2011).

The development of language in deaf children is complicated. It is important to find an easy and effective means to communicate with a deaf child and this may involve either sign or spoken language. In some cases, it is clear that language development for profoundly deaf children begins early on and takes place entirely through visual, 
gestural, and sign language (Lederberg et al., 2013). They have limited access to language because $95 \%$ of such children have parents who can hear well (Mitchell \& Karchmer, 2004). The environment in which deaf children grow up are mostly hearing oriented. They may not be exposed to sign language from an early age. This may, in some cases, lead to the creation of fewer opportunities for a child to obtain language. The basic difficulty that a deaf child encounters is being cut off from the ordinary speech environment (Webster, 2017). Therefore, it is not the loss of sound that is the basic challenge of deafness, but rather the language deficiency that is caused by the environment in which a child grows up (Lederberg et al., 2013).

The level of proficiency among deaf children plays a significant role in language development. For example, when deaf children engage with two languages such as sign and spoken/written language at the same time, their level of proficiency affects the extent of their mastery over language ( Paul, 2009; Pichler \& Koulidobrova, 2015). It may be argued that with such interactions, deaf children may produce different modes of language development. A deaf child's interactions with the people around them such as their parents, are very important as these interactions can affect their rate of language development. Deaf children of deaf parents may benefit from linguistic interactions from the time of birth, and this development of language is natural (Klatter-Folmer et al., 2006). There is evidence that deaf children acquire sign language at a rate that is similar to that of hearing children (Harley, 2013). Deaf children with hearing parents find it far more difficult to acquire language as they do not have the opportunity to access language that deaf children with deaf parents do (Klatter-Folmer et al., 2006). Deaf children with hearing parents wind up using complex gestures to communicate (Morgenstern et al., 2010). Irrespective of whether their parents can hear or are deaf, deaf children who had an early diagnosis of deafness and the opportunity for early language development tend to have good language (Marschark et al., 2001). Given that language acquisition is essential, deaf children should be given all opportunities for language development, such as a favourable linguistic environment and accessible language, at least in the early years of their lives (Mathews, 2017).

\section{Language skills and Literacy among Deaf Children}

There is a link between language fluency and the acquisition of literacy skills where the latter can enhance language fluency. Deaf children who begin schooling with some language abilities have a relatively easier time making the move to textbased literacy than deaf children who may be entirely without linguistic experience (Mayer, 2007). Literacy skills comprise two components, namely reading and writing. It is a subcomponent of a higher-order category that also includes direct person-to-person oral and manual communication (Garberoglio et al., 2014).

Reading and writing have a strong interrelationship, wherein writing facilitates the development of reading and reading facilitates the development of writing (Paul, 1998). Kress (2005) noted that reading is learned first and writing follows suit on most occasions. Deaf children struggle with both skillsets, particularly in areas such as comprehension (Harris et al., 2017; Kyle \& Cain, 2015; Luckner \& Handley, 2008), inferential comprehension (Kyle \& Cain, 2015), word recognition (Kyle \& Cain, 2015;Kyle \& Harris, 2010), reading fluency (Luckner \& Urbach, 2012), morphological knowledge (Trussell \& Easterbrooks, 2017), and genre knowledge (Luckner \& Handley, 2008).

\subsection{Writing Skills of Deaf Children}

Acquiring writing skills can be difficult for all types of children, both deaf and hearing child. One of the main issues that deaf children face is learning and using spoken language. For most people, speech is the primary means of communication and deaf children who cannot 
speak encounter difficulties while communicating with the world. There are other ways to communicate such as sign language, lip-reading, and gesticulation, but hearing people may not understand these modes. Therefore, writing is especially important to deaf children as it enables them to communicate with the world (Wolbers et al. 2012). There are two levels in writing. At a fundamental level, writers must produce letters, words, and sentences. This means that students must know the conventions of spelling and punctuation and use appropriate vocabulary and syntactic structures. At a deeper level, they must be able to choose a subject, plan and arrange ideas, and make decisions pertaining to the information that they want to focus on in their writing (Powers \& Wilgus, 1983).

Paul (1998) identified three stages of writing: planning, composing, and revising. The first stage, planning, refers to generating and organising ideas and identifying the audience for the proposed piece of writing. The second stage is the actual production of the first draft. The third stage refers to reviewing and editing what has been written. Heaton (1988: p 135) indicated that the following skills are involved in writing:

1. Language use, or the ability to write correct sentences and words.

2. Stylistic skills, or the ability to manipulate sentences and use language effectively.

3. Mechanical skills, or the ability to use conventions peculiar to the written language such as punctuation, paragraphing, and spelling correctly.

4. Judgement skills, or the ability to write for a particular purpose in an appropriate manner with a particular audience in mind and the ability to select, arrange, and order relevant information.

Moors (2001) believed that a deaf person's ability to communicate with hearing people may rely heavily on their writing skills. A deaf person can resort to compensatory strategies to understand a message when their grammar and vocabulary skills are limited (Cannon \& Kirby, 2013). However, it is far more difficult to express oneself clearly while writing with these limitations. There are differences between students who use written language and students who use spoken language in terms of the level of awareness that is required of the speaker (Hulme \& Snowling, 2014). Written language on the other hand, 'requires an explicit awareness, knowledge of how the code is put together and how it works' (Webster, 1986).

\subsubsection{Approaches Towards Developing Writing Skills}

There are several approaches towards developing one's writing skills. This section presents a brief overview of these approaches with a specific focus on deaf learners. The most cited approach for the development of writing skills is the sociocognitive approach that aims to investigate and accomplish two important goals. First, it aims to explore the cognition that a learner takes out of naturalistic settings ( Marschark \& Hauser, 2008). Second, it explores the diverse samples of writers and materials attempting to address a variety of cognitive styles and recognises social experiences and literacy practices that student writers bring to the process of writing ( Marschark \& Hauser, 2008).

Berkenkotter and Huckin (1995, quoted in Marschark \& Hauser, 2008) noticed that the most recently emergent theories (e.g genre analysis') and research have emphasised on the influence of studies in the area of 'genre analyses' on writing. 'Genre' is a standard form of textual discourse such as stories, recommendations, or literature reviews. Marschark and Hauser (2008) argued that one key difference between novice and expert writing is the ability to move from one genre to another, and to adapt to different contextual situations, including different academic areas. They also mentioned that socio-cognitive approaches towards instructions adapting a 'genre approach' are recommended as learners will be more competent to write more effectively if they understand the goals and features of the target 
genre. When learners 'are made aware of the fact that they are writing to accomplish different goals in different contexts that require different strategic language usage, they will be more successful at their own writing projects' (Marschark \& Hauser, 2008).

Williams and Mayer (2015) reviewed the literature on the development, instruction, and assessment of writing among deaf children aged 3 to 8 years. They found that most of the work had concentrated on spelling and when the focus was on the production of writing, the analyses were limited to the word level alone.

Other methods of teaching and evaluating the literacy skills of deaf students have focused on understanding their competencies. Marschark and Hauser (2008) conducted research by integrating deaf students into the processes of writing in 'writing across the curriculum' (WAC) and 'writing in the disciplines' (WID). They stated that some of the opinions expressed by key WAC and WID researchers supported the idea that there are not only specialised ways of writing, but also of learning. Thus, if writing and learning are related to knowledge acquisition in a given discipline, writing will effectively promote content learning. The theory and practice of WAC and WID have prospered as major strategies in teaching academic writing. They have often resulted in writing-intensive courses. Marschark and Hauser (2008) noted that WAC and WID are in line with the best practices in deaf education that emphasise the connections among reading, writing, and learning.

\subsubsection{Attainments of Deaf Children in Writing}

Research has also focused on attainments of deaf children in writing. Marschark and Hauser (2008) noted in 1960s the learning requirements of deaf children received extensive attention, and an expansive proliferation of empirical research on the process of thinking while writing followed. However, research conducted throughout the 1970s and early 1980s was restricted to methods such as Think-Aloud or Read-Aloud Protocol
Analysis to identify the cognitive processes that writers relied on in the production of text (Marschark and Hauser, 2008).

Deaf children encounter problems in the course of developing their literary and cognitive skills and this may result difficulty in writing. Several examples of these difficulties have been highlighted throughout the literature. for example, identified that deaf children encounter some difficulty in writing skills, in areas such as (1) drawing analogies, (2) working with similes, and using metaphors with (3) specific and (4) nonspecific referents (Mcanally, et al. 1987). Comparing deaf students with their peers who can hear, Volterra and Bates (1989) noticed some differences in writing between both classes. They claimed that deaf students usually (1) generate shorter sentences, (2) avoid complicated syntactic constructs, (3) use a more limited vocabulary, (4) often delete function words (e.g. articles and prepositions) and, on some occasions, use more words than required, (5) often remove major components of the sentence (e.g. the verb 'to be' or auxiliary verbs), and (6) form sentences with incorrect word orders.

A few deaf children can write ideas in auditory style, which may be very difficult as translating such ideas into writing can be challenging. Different techniques are used to analyse deaf children's writing. Yoshinaga-Itano and Snyder (1985) identified five different types of analyses:

1. Quantity of sentences and length of composition,

2. Complexity of syntactic forms used in sentences and composition development,

3. Analysis and categorisation of errors in the composition,

4. Quantitative use of various parts of speech, and

5. Quantitative analysis of various types of transformational grammatical structures used.

Very few studies have discussed the development of vocabulary in deaf children (Luckner \& Cooke, 
2010; Pizzo, 2018). These studies have showed that the level of vocabulary is lower for students with deafness than among those who can hear. Deaf children use more simple syntactic structures including nouns, verbs, and determinants, and make less regular use of adverbs, auxiliaries, and conjunctions than do hearing children (Kilpatrick 2015). Several studies that have examined deaf writing have mostly focused on English as the medium of writing (Harris et al., 2017; Moores \& Miller, 2009; Marschark \& Spencer, 2010). Other studies have identified the difficulties encountered by deaf children in learning other languages such as Italian (Fabbretti et al., 1998) and Hebrew (Tur-Kaspa \& Dromi, 2001). Therefore, it can be concluded that difficulties are not language specific.

Quigley and King (1980) examined the writing language of 450 deaf children aged between 10 and 19 years. They did not provide any information on the children's language backgrounds. The analysis focused on syntactic structures and they found that deaf children made many errors in word order, use of pronouns, conjunctions, and verb inflection. Musselman and Szanto (1998) divided a sample of 69 students into two groups, wherein one comprised 15 students who used auditory/oral communication and the other comprised 54 who used sign language. They found that students who used auditory/oral communication scored higher in their writing and general academic achievement than those who used sign language. From the first group, 14 students had been educated in generaleducation classrooms. In the second group, 37 had been educated in segregated classrooms.

Yoshinaga-Itano and Downey (1996) studied the written language skills of 94 hearing students and 461 deaf students aged between 7 and 18 years in different educational settings. They found that an increased degree of deafness delayed the acquisition of written language skills further. They also reported that deaf students experienced delays in the acquisition of written language skills at all ages when compared with hearing students. Another finding explained that students who used auditory/oral communication experienced fewer delays in acquiring writing skills than children who used sign language.

\subsection{Reading Skills Among Deaf Children}

Reading is a highly complex process comprising several interrelated sub-processes; the reader actively brings past knowledge and expectations to the process and anticipates what they will encounter in text-predictions that may be modified in the course of reading (Moores, 2001). Moores (2001) found that in most school programmes, all children usually pay more attention to reading than to writing, as it is seen as a resource for acquiring knowledge and engaging in society; this is especially true if they are deaf. He also said that we learn to read in the early years at school, and then read to learn. Reading is a core skill that can impact performance in other academic areas. Students who find it difficult to read will also find it difficult to handle other academic subjects.

Reading requires two important skills: familiarity with spoken language, and (2) understanding the mapping between that language and the printed word (Chamberlain \& Mayberry, 2008). Reading is a complicated process that includes 'the active construction of meaning from text, using linguistic knowledge and the decoding of letters and words, as well as higher-order processes, such as metacognitive strategies' (Brown \& Brewer, 1996). Schirmer and McGough (2005) identified four components of metacognition: (a) knowing when you comprehend, (b) knowing what you comprehend, (c) knowing what information you need to learn to understand, and (d) knowing how to invoke techniques to enhance comprehension. All these strategies seem inextricably linked and require a high degree of autonomy on part of the reader.

\subsubsection{Approaches for Reading Development}

A number of approaches and models address the learning and development of reading skills. For example, the 'simple view of reading', developed 
by Gough and Tunmer (1986) provides a good starting point for understanding reading processes. It comprises two key factors, namely 'decoding' and 'oral language', which include reading comprehension as their product. This approach sees reading comprehension as a form of linguistic comprehension that enters the brain through visual decoding. Decoding is the process of interpreting the symbols on a page into a word in the reader's aural vocabulary bank. Oral language comprehension facilitates the interpretation of the meaning of words. The relationship between decoding and oral language can be conceptualised in the following manner: decoding the text (recognising words in text and sounding them out phonemically) facilitates oral language comprehension (ability to understand language), and this leads to reading comprehension (ability to read and obtain meaning from what is read) (Gough \& Tunmer, 1986). The ability to decode words is essential for skilled reading. Those with either very low decoding skills or very poor comprehension abilities will be weak at reading. Decoding or reading words is often a bottleneck that prevents readers from gaining a higher or more satisfactory understanding of the text (Kirby, 2007).

Deaf learners will encounter certain difficulties in taking the first step in this approach, that is, decoding the words. This may be because they may have rather limited vocabulary and more particularly synonyms. Other approaches to develop reading skills include the 'bottom-up' and 'top-down' approaches, as well as a mixture of the two. 'Bottom-up' approaches simply suggest that the reading process begins with the print on the page. Taking clues from the written features such as letters, the reader works upwards towards 'higher' levels of words and sentences, until the entire meaning is discerned. In the process, words are used to form phrases, and phrases are used to articulate ideas; and the knowledge of syntax (grammar) is very important (Webster, 1986; Paul, 2009). The 'top-down' approach suggests that reading is guided by decisions made by the brain. Webster (1986) claimed that top-down processing needs prior knowledge to decide and see the deeper implications of the text. It is important to recognise that both bottom-up and top-down processing occurs frequently in reading comprehension.

\subsubsection{Attainments of Deaf Children in Reading}

Studies have shown that deaf readers encounter difficulties in acquiring several reading skills, and have also found that deaf students are weaker when compared to hearing students in many areas associated with linguistic comprehension such as metacognitive strategies and word identification (Luckner \& Handley, 2008; Moeller et al., 2010; P. Paul, 2003); memory span; attention span, wherein deaf children have a low attention span and may not be able to organise their knowledge and long and short term memory processes ( Marschark \& Maye, 1998; Marschark \& Spencer, 2010); knowledge of syntax ( Traxler et al., 2014); P. Paul, 2003); figurative language (P. Paul, 2003); grammar(Traxler et al., 2014); vocabulary size (Pizzo, 2018); reading fluency (Luckner \& Urbach, 2012); and morphological knowledge (Trussell \& Easterbrooks, 2017; Luckner \& Handley, 2008).

Deaf students generally score lower on standardised measures of reading comprehension than their peers who can hear. Mitchell and Karchmer (2004) identified a gap in the average reading comprehension performance for 15-yearold deaf and hearing students, over a period of six years, in the ninth edition of the Stanford Achievement Test. Similarly, Marschark and Harris (1996) reported that the reading level of a deaf high school graduate is on average the same as that of an eight or nine year old child who can hear. Allen (1986; in Marschark, 1993) found that the lags in reading comprehension that deaf children experience in school when compared to their peers who can hear tend to increase over the years at school. Difrancesca (1972; in Marschark, 1993) found that in a sample of 17,000 deaf 
children aged between 6 and 21 years, reading scores had increased by only 0.2 grade levels per academic year. Hermans, et al., 2008 studied the relationship between reading skills and sign language and found that highly developed sign language are linked to high levels of readability for deaf people who primarily use sign language.

\section{Factors Influencing Language Development}

Deaf children come from different socioeconomic backgrounds, have different ages of onset and degrees of deafness, and may or may not use hearing aids. Some of these factors may have an impact on language development and other aspects of the personality development of deaf children (Moores \& Miller, 2009). Deafness itself is as wide and complicated as the range of social and historical backgrounds of the deaf children themselves (Knight \& Swanwick, 1999).

This section discusses the major factors that influence language development of reading and writing skills by deaf children.

\subsection{Onset of Hearing Loss}

The first 36 months of childhood constitute the most critical period for language acquisition; language development is never as rapid after this period (Klatter-Folmer et al., 2006; Kushalnagar et al., 2010). The age of hearing loss plays a critical role in language development. However, there are many reasons for and causes of deafness. Some children may be deaf from birth and others may acquire deafness later in life. Children acquire speaking skills at an early age by communicating with members of the family and by imitating the speech they hear.

\subsection{Degree of Hearing Loss}

The degree of hearing loss can vary from person to person (McCreery et al., 2015), and is classified as mild (20-40), moderate (41-70), severe (71-95), and profound $(95+) \mathrm{dB}$. These categories are used by the British Association of Teachers of the Deaf. Children with a lower level of hearing impairment are likely to use speech to communicate. Those with a greater level of hearing loss are more likely to use sign language.
Tomblin et al. (2015) found that children with mild to serious hearing loss are at risk of experiencing delays in linguistic development, and also noted that better degrees of audibility are associated with growth in language.

\subsection{Age of intervention}

Researchers have attempted to explore the factors affecting reading outcomes among deaf children. Some of the underperformance in language among deaf children has been the result of delayed detection and intervention. The age of intervention is a robust indicator for later reading capabilities (Archbold et al., 2008; Mayer et al., 2016; Connor \& Zwolan, 2004). Universal Neonatal Hearing Screening claimed that when deaf children are diagnosed early, it will lead to early interventions such as cochlear implant surgery. Research has shown that the ideal age for intervention is six months (Yoshinaga-Itano, 2004).

The identification of deafness before the age of six months can increase the probability of language development in deaf children. The early appropriate intervention programme should include family counselling, fitting of hearing aids, auditory therapy, language learning, and educational strategies based on the needs and abilities of the child. Early detection and intervention have the greatest impact on the development of speech and language. On the other hand, late identification and intervention for deafness may lead to the development of a limited vocabulary and difficulties with grammar. Tomblin et al. (2014) analysed the impact of hearing aids on language development in children with mild to severe hearing loss. They studied 180 deaf children, between ages 3 and 5. They found that the degree of enhancement of hearing ability through the use of hearing aids was associated with language development in children.

Some deaf children use hearing aids and undergo cochlear implant procedures to hear better. Deaf children who used hearing aids from an early age 
onward had greater advantages (e.g. educationally and linguistically) than those who used them at a later stage (Nicholas \& Geers 2006). The use of hearing aids has benefits for both language development and communication (Bunta et al., 2016; Robbins et al., 2004; Teschendorf et al., 2010, 2011; Thomas et al., 2008).

Penna et al. (2015) examined the effect of hearing aids on the linguistic profiles and the hearing skills of children. They investigated a nonprobabilistic sample of 110 children aged between 6 and 10 years, who used hearing aids to address mild to profound hearing loss. Four types of tests were performed: language, speech perception, phonemic discrimination, and school performance tests. They found that $65 \%$ of the children had altered vocabulary, whereas $89 \%$ and $94 \%$ had altered phonology and inferior school performance, respectively. They also found that the late identification and intervention contributed to losses in language development.

\subsection{Family}

Communication between family members and deaf children at home plays an important role in developing the deaf children language (Anderson, 2006; Crowe et al., 2012; Hintermair, 2015). Communication with deaf children from an early stage can help them understand language faster. The parents' ability to hear and the mode of communication they use can also affect the acquisition of language by deaf children. Deaf children with deaf parents are more likely to use sign language as communication means(Anderson, 2006; Fitzpatrick et al., 2016). Deaf children with hearing parents may experience difficulty in communication because the parents' use of spoken language. Sign language is not usually available in the early years of their life. Spencer and Harris (2006) noted the wide variations in sign language received by deaf children and found that there are differences among hearing mothers and their language provision to their deaf children, wherein most of them had not had any prior experience using signs to interact with deaf people. However, deaf mothers, who are known to differ from hearing mothers, usually position their signing within the child's visual field while making their language more perceptible for their deaf children, and wait for the child's gaze to establish before they begin communicating (Spencer \& Harris, 2006). Deaf children from deaf families have better linguistic skills and achieve higher academic standards than deaf children born to hearing parents (Lederberg et al., 2013). The quality of interaction, either by sign or spoken language, also influences language development. In mother-child interactions, it is clear that the mother is not only talking and communicating with her child but is also encouraging her child to respond to her. Mothers' ways may change based on the child's age and degree of expressive language (Cruz et al., 2013). Deaf children may experience differences in social interaction where the quality and quantity of play interaction between deaf children and their deaf or hearing peers pertain to communication fluency (Marschark et al., 2001). Research has shown that deaf students with deaf parents who relied on sign language for communication from birth did better at reading and writing than deaf children with hearing parents (Hermans et al., 2008)

\subsection{Socio-economic Background}

This factor relates to the previous one, as the socio-economic background of a child influences its language development and abilities. A child who grows up in a better socio-economic background experiences better linguistic development because the socio-economic background (Lederberg et al., 2013). It provides the child with better space for communication and offers exposure to appropriate stimuli (e.g. going on trips, reading books, etc). The Department of Health and Human Services in the US (Harmer, 1999) reported that deaf people, on average, had low incomes. School-going children from lowincome backgrounds are more likely to encounter problems with academic attainment, including language development (Waber et al., 2006; 
Marschark and Hauser, 2008). Deaf children from low socio-economic backgrounds tend to have poor language development levels than children from moderately higher socio-economic backgrounds (Noble et al., 2005, Hoff, 2013; Zhang et al., 2013). Research has showed that socio-economic statuses significantly affect literacy development. Twitchell et al. (2015) evaluated the effects of socio-economic status and the degree of sign language skills on the English reading skills of 135 deaf students. Though socioeconomic status and sign language proficiency were not correlated in this sample, both factors were obviously predictors of reading skill.

The level of education of parents is also an important determinant of deaf children's linguistic abilities. Better educated parents may provide better learning situations and offer their children higher stimuli (Eyalati et al., 2013). They may not usually wait for their children to ask for things or wait to notice a problem with their children's language abilities as they may already be familiar with their needs for a supportive learning environment.

\subsection{Physical Conditions/Learning Difficulties}

A child's physical condition has a major impact on language development. The focus here is on the larynx, lips, tongue, ears, eyes, and brain. When a child is physically, emotionally, and behaviourally fit, they are more capable of developing their language skills (Levickis et al., 2018).The hearing, vocal, visual, neural, and mental capacities all have direct influences on a language development because any type of impairment can affect the child adversely (Lee et.al., 2013). For example, a deaf child would be less active than a hearing child, and less action can result in slower language development (Cupples et al., 2014; Guardino, 2015; ; Chilosi et al., 2010; Guardino, 2008). The Health Advisory Services (Gregory et.al, 1998) showed that 40 to $50 \%$ of deaf children have emotional, behavioural problems, or both. These problems can impact language development as well. However, the state of hearing abilities, and the vocal and mental systems have the greatest impact on a child's language development (Bruce \& Borders, 2015). Cupples et al. (2018) investigated language development in young deaf children and other different types of disabilities (autism, cerebral palsy, and/or developmental delay) as well. A total of 67 children were examined and they are from 3 to 5 years. The study used the Preschool Language Scale (Fourth Edition) and the Peabody Picture Vocabulary Test. They found that the children's language levels remained stable over the two years under study. This stability varied significantly across children with different types of disabilities. Children with autism, cerebral palsy, and/or developmental delays presented a drop in scores, whereas children with other types of disabilities presented a relative improvement. They found that the type of additional disability also affected language development in deaf children.

\subsection{Communication Media}

What a child receives from the communication media provided to it can also affect language development. When a child, for example, watches a television programme, they learn from what they are watching. Televisions are found everywhere in society and can be used for education at homes, as well as in nursery and preschool settings. Televisions contribute to the learning process by being a part of the environment surrounding a child (Easterbrooks \& Stoner, 2006). When a family allows a child to watch particular programmes on television, the child receives the language used in such programmes and develops its language skills accordingly. For example, educational programmes can help children learn the alphabet and develop their academic vocabulary. Television plays a significant role in influencing children's learning (language development) and socialisation skills; further, deaf children seem interested and watch television more than their peers who can hear (Lewis \& Jackson, 2001). However, the benefit of watching 
television depends on the choice of programme as well. Linn (2007) examined the effect of watching television on a baby's language development and suggested that television and DVDs are not useful for the development of language for babies. Children who spend more time watching such media have a slower rate of language development than children who spend less time.

On the other hand, a number of studies have found that using appropriate educational television programmes can successfully raise the literacy skills of preschool hearing children. However, only a few studies have examined whether this method can be effective for deaf children at the preschool level. Golos (2010) investigated the type and frequency of literacy skills that deaf students can integrate into the process of watching educational videos delivered in sign language. Deaf children were recorded while watching the educational video, over three sessions. The videos were coded for literacy-related engagement behaviours. The results showed that preschool deaf children relied on a number of literacy skills and behaviours regardless of their age and the extent of access they had to sign language, and that these behaviours changed after they watched multiple videos.

Educational media has been increasingly relied on as a tool to enhance the development of deaf children's language and literacy skills. For example, Golos and Moses (2013) examined 31 deaf children in preschool to identify the extent of their American Sign Language and literacy skills after watching one video from an educational video series on sign language. They found a significant improvement in the skills targeted in the video among all participants regardless of the level of the baseline ASL skills. The results showed that learning sign language and acquiring literacy skills using educational media can benefit deaf children with varied degrees of exposure to sign language.

Educators of deaf children have expressed their concern over the lack of curricular resources that are suitable for and beneficial to deaf children (Alothman, 2014). They have suggested that early childhood classrooms need appropriate materials, particularly for language and literacy development. Teachers may not be fluent in sign language. Therefore, it is necessary for educational tools to support and expand the language and literacy skills of deaf children.

\section{Approaches to Language Learning}

Although there are a number of approaches and models that tackle acquiring, learning, and teaching language, two approaches are used and quoted in this study: the natural and the structured approaches. Both have been used to teach both deaf children and those who can hear (Paul, 2009). These approaches have been adopted and used to enhance language development in educational settings (Higgins \& Lieberman, 2016).

\subsection{The Natural Approach}

This approach indicates that the major purpose of a language is to facilitate communication. It notes that for deaf children to acquire communication skills, they need to be 'exposed' to language through day-to-day communication that occurs 'naturally' in their environments (Krashen \& Terrell, 1983). It acknowledges that children do not usually follow a systematic approach to learn a language at home or in class, but rather that language is acquired and developed by children comfortably and easily in social settings and through unconscious efforts (Krashen \& Terrell, 1983). This approach focuses on the acquisition of a language through meaningful real-life situations and involves the development of colloquial and idiomatic expressions (Paul, 2009).

Guardino and Antia (2012) believed that classroom environment, peers and teachers are also support deaf children in acquiring and developing their language skills. The natural approach indicates that teachers should be familiar with the words and structures that each child needs in order to communicate effectively. It also emphasises that teachers should help learners 
develop their language skills through natural and contextual methods by bringing the children's experiences, interests, and needs into class. The natural approach has been useful in language intervention programmes as it empowers the pragmatic interests of learners.

\subsection{The Structured Approach}

The structured approach is frequently referred to as the 'formal', 'grammatical', or 'analytical' method (Mcanally et al., 1987). It requires students to engage in meta-linguistic behaviour. For example, it requires the explicit study, analysis, and categorisation of grammatical and structural aspects of a language by a learner, such as parts of speech (nouns, verbs, and objects) (Paul, 2001).

Mcanally et al., (1987) offered a set of principles that apply to the structured approach. These principles can also support language instruction. Teachers who handle both deaf and hearing children may find these principles helpful in the development of instructional units and activities focusing on morphological and syntactic skills. These principles are as follows:

1. Unfamiliar words and sentence formation rules should be presented according to normal language developmental sequences or established orders of difficulty.

2. Words featured in the phrases, clauses, and sentences used for intervention should be highly familiar.

3. Knowledge of word or sentence formation rules should be established first in recognition and comprehension tasks, and then in formulation tasks.

4. The knowledge and control of word and sentence formation rules should be established first with highly familiar word choices.

\subsection{Approaches Towards Supporting Language Learning Needs of Deaf Children}

Although the approaches to language development for typical children may provide interesting insights, greater focus on approaches dealing with deaf children is necessary. The most influential approaches addressing language development among deaf children include the auditory/oral, the total communication, and the bilingual-bicultural approaches. Each approach is discussed separately below.

\subsubsection{Auditory/Oral Approach}

This approach highlights the importance of developing language skills for deaf children, and aims to help them receive and understand language through their residual hearing (auditory) and lip-reading/spoken language (oral) skills (Wearmouth et al., 2017). This approach suggests that the development of language takes place through spoken language where a learner acquires language through hearing and speech, and the emphasis is often on listening skills and the development of speech and lip-reading skills. It is believed to be superior to others as it empowers learners to understand and communicate better with hearing people. This approach relates to and reflects on the natural approach mentioned above as it aims to empower learners so that they can receive language in a more natural fashion. A deaf person can extract information on the structure of spoken language by observing the movement of the lips, jaws, and face of the speaker (AuerJr \& Bernstein, 2007). However, lip-reading skills among deaf people are related to the extent of their understanding of oral language (Dye \& Pascalis, 2017)

Studies have also focused on the differences among deaf lip-readers. MacSweeney et al. (2001) examined the differences in the lip-reading skills between deaf and hearing children. In this study, both types of children were asked to lipread numbers from 1 to 9 , rendered silently. The authors found that temporal activation was more discrete on different sites and less intense among the deaf participants . In a second study, MacSweeney et al. (2002) found that the cortex was more activated during lip-reading in deaf people than in those who could hear. 
Kyle et al. (2013) described a new test to examine speech reading skills among both deaf and hearing children. They examined the effects of hearing status, age, and linguistic complexity on the ability to lip read. The test examined lip-reading for each child at three levels: words, sentences, and short stories. They examined 86 deaf children and 91 hearing children, all aged between 5 and 14 years. The deaf children came from different backgrounds and their preferred modes of communication varied. The study concluded that lip-reading skills showed significant improvements with age for both deaf and hearing children.

\subsubsection{Total Communication Approach}

The total communication approach requires that a deaf child be given the maximum opportunity to access a language. This approach allows learners to communicate using a range of mediums, such as speech, lip-reading, gesticulation, reading, writing, finger spelling, and sign language ( Kyle et al., 2013; MacSweeney et al., 2002). Al-Rayes (2005) highly recommended this approach for use in teaching deaf children, as it provides the learner with the ease of using the method that is best for them in any given context. This approach emphasises the individuality of each learner and gives them room to rely on the methods that suit them best in developing their language and in communicating with others (Allen \& Anderson, 2010). The most common interpretation of the total communication approach involves the use of both spoken and sign language simultaneously.

\subsubsection{The Bilingual-bicultural Approach}

The bilingual-bicultural approach treats sign language as the 'common' and 'natural' mode of communication for deaf children (Higgins \& Lieberman, 2016). It requires deaf children to be exposed to sign language as their 'first' or 'preferred' language and form of communication. The early years are known as the optimal age for linguistic development in the bilingual approach. It requires deaf children to learn and develop their sign language from early childhood onward. The bilingual-bicultural approach encourages the use of sign language as the deaf community's 'natural first language' and also highlights the importance of learning and developing skills in a 'second language' for deaf children, and recommends a community spoken language for reading and writing (Hrastinski, \& Wilbur, 2016; Leigh, \& Johnston, 2004) The phrase 'sign bilingualism' is referred to two languages, namely 'sign' and 'spoken/written' languages, together.

The early years have a significant impact on the long-term achievement and wellbeing of deaf children, and early exposure to fluent linguistic and supportive cultural role models is important in early childhood environments. However, there are different perspectives on how early childhood environments can help deaf children learn better. Golos et al. (2018) investigated how early childhood settings should help deaf children learn. They examined the reliance on cultural and linguistic roles in early childhood environments and instruction and found that classrooms differ in terms of the type and frequency of cultural and linguistic providers and based on the type of communication used in the classroom, the teachers' hearing level, and the level of their sign language.

Some studies have examined social inclusion and its effects on improvements in language and literacy skills among deaf children. Constantinescu et al. (2015) investigated the effect of spoken language on social inclusion among 95 deaf children who were aged 5 years. Relying on factors such as 'education' and 'interacting with society and fulfilling social roles', they found that social inclusion was influenced by speech abilities and vocabulary. They also found that vocabulary skills developed when deaf children were integrated into social activities such as birthday parties (Constantinescu et al., 2015). Constantinescu-Sharpe et al. (2017) examined two aspects of social inclusion, namely 'education' and 'interacting with society and fulfilling social goals'. They surveyed the parents of deaf children 
aged 4 and 5 years. They found that most deaf children showed results that were comparable with those of hearing children.

\section{Conclusion}

This study has examined some of the relevant literature on deaf children and their language development (reading and writing) journeys. The literature review in this paper discussed two approaches towards the education of deaf children. Furthermore, it discussed the effect of deafness on language development, and how the limitations of visual perceptions can influence the act of receiving language. It also highlighted the importance of early access to communication. Also, it showed the most factors influencing language development among deaf children are the onset and degree of deafness, the use of hearing aids, and family and socio-economic backgrounds.

This study can offer room for both information to be derived while framing strategic directions for teachers handling deaf children, as well as future research in the field by building on the panorama of the literature shown. In conclusion, it is important to highlight that approaches to language learning offer situational strategies that adopt a mix of different approaches based on the conditions determined by the learner and the environment.

\section{Acknowledgments:}

The author extend his appreciation to the Deanship of Scientific Research at. Majmaah University for supporting this work.

\section{References}

[1] Al-Rayes, T. (2005) Bilingual bicultural. Paper presented at the symposium of special education. Riyadh: King Saud University.

[2] Allen, T. E., \& Anderson, M. L. (2010). Deaf students and their classroom communication: An evaluation of higher order categorical interactions among school and background characteristics. Journal of Deaf Studies and Deaf Education, 15(4), 334-347.

Alothman, A. (2014). Inclusive Education for Deaf Students in Saudi Arabia: Perceptions of Schools Principals, Teachers and Parents. 322.

[4] Anderson, D. (2006). Lexical development of deaf children acquiring signed languages. Advances in the Sign Language Development of Deaf Children, 135-160.

[5] AuerJr, E. T., \& Bernstein, L. E. (2007). Enhanced visual speech perception in individuals with early-onset hearing impairment. Journal of Speech, Language, and Hearing Research.

[6] Brown, P. M., \& Brewer, L. C. (1996). Cognitive processes of deaf and hearing skilled and less skilled readers. The Journal of Deaf Studies and Deaf Education, 1(4), 263-270.

[7] Bruce, S. M., \& Borders, C. (2015). Communication and language in learners who are deaf and hard of hearing with disabilities: Theories, research, and practice. American Annals of the Deaf, 160(4), 368-384. https://www.ncbi.nlm.nih.gov/pubmed/264 97075

[8] Bunta, F., Douglas, M., Dickson, H., Cantu, A., Wickesberg, J., \& Gifford, R. H. (2016). Dual language versus Englishonly support for bilingual children with hearing loss who use cochlear implants and hearing aids. International Journal of Language \& Communication Disorders, 51(4), 460-472. https://www.ncbi.nlm.nih.gov/pubmed/270 17913

[9] Cannon, J. E., \& Kirby, S. (2013). Grammar structures and deaf and hard of hearing students: A review of past performance and a report of new findings. 
American Annals of the Deaf, 158(3), 292-310.

https://www.ncbi.nlm.nih.gov/pubmed/241 33956

[10] Chamberlain, C., \& Mayberry, R. I. (2008). American Sign Language syntactic and narrative comprehension in skilled and less skilled readers: Bilingual and bimodal evidence for the linguistic basis of reading. Applied Psycholinguistics, 29(3), 367388.

[11] Chilosi, A. M., Comparini, A., Scusa, M. F., Berrettini, S., Forli, F., Battini, R., Cipriani, P., \& Cioni, G. (2010). Neurodevelopmental disorders in children with severe to profound sensorineural hearing loss: A clinical study. Developmental Medicine \& Child Neurology, 52(9), 856-862.

[12] Constantinescu, G., Phillips, R. L., Davis, A., Dornan, D., \& Hogan, A. (2015). Exploring the impact of spoken language on social inclusion for children with hearing loss in listening and spoken language early intervention. The Volta Review, 115(2), 153-181.

[13] Constantinescu-Sharpe, G., Phillips, R. L., Davis, A., Dornan, D., \& Hogan, A. (2017). Social inclusion for children with hearing loss in listening and spoken Language early intervention: An exploratory study. BMC Pediatrics, 17(1), 74.

[14] Crowe, K., McLeod, S., \& Ching, T. Y. (2012). The cultural and linguistic diversity of 3-year-old children with hearing loss. Journal of Deaf Studies and Deaf Education, 17(4), 421-438.

[15] Cruz, I., Quittner, A. L., Marker, C., DesJardin, J. L., \& Team, Cd. I. (2013). Identification of effective strategies to promote language in deaf children with cochlear implants. Child Development, $84(2)$,

543-559. https://www.ncbi.nlm.nih.gov/pmc/articles /PMC3530629/

[16] Cupples, L., Ching, T. Y., Crowe, K., Seeto, M., Leigh, G., Street, L., Day, J., Marnane, V., \& Thomson, J. (2014). Outcomes of 3-year-old children with hearing loss and different types of additional disabilities. Journal of Deaf Studies and Deaf Education, 19(1), 20-39.

[17] Cupples, L., Ching, T. Y., Leigh, G., Martin, L., Gunnourie, M., Button, L., Marnane, V., Hou, S., Zhang, V., \& Flynn, C. (2018). Language development in deaf or hard-of-hearing children with additional disabilities: Type matters! Journal of Intellectual Disability Research, 62(6), 532-543.

https://www.ncbi.nlm.nih.gov/pubmed/297 32729

[18] Dye, M., \& Pascalis, O. (2017). The Impact of Sensory, Linguistic and Social Deprivation on Cognition. Frontiers Media SA.

[19] Easterbrooks, S. R., Lederberg, A. R., \& Connor, C. M. (2010). Contributions of the emergent literacy environment to literacy outcomes for young children who are deaf. American Annals of the Deaf, 155(4), 467-480.

https://www.ncbi.nlm.nih.gov/pubmed/213 05981

[20] Easterbrooks, S. R., \& Stoner, M. (2006). Using a visual tool to increase adjectives in the written language of students who are deaf or hard of hearing. Communication Disorders Quarterly, 27(2), 95-109. https://journals.sagepub.com/doi/10.1177/ 15257401060270020701

[21] Eyalati, N., Jafari, Z., Ashayeri, H., Salehi, M., \& Kamali, M. (2013). Effects of parental education level and economic status on the needs of families of hearingimpaired children in the aural 
rehabilitation program. Iranian Journal of Otorhinolaryngology, 25(70), 41.

[22] Fabbretti, D., Volterra, V., \& Pontecorvo, C. (1998). Written language abilities in deaf Italians. The Journal of Deaf Studies and Deaf Education, 3(3), 231-244.

[23] Fitzpatrick, E. M., Hamel, C., Stevens, A., Pratt, M., Moher, D., Doucet, S. P., Neuss, D., Bernstein, A., \& Na, E. (2016). Sign language and spoken language for children with hearing loss: A systematic review. Pediatrics, 137(1), e20151974.

[24] Freel, B. L., Clark, M. D., Anderson, M. L., Gilbert, G. L., Musyoka, M. M., \& Hauser, P. C. (2011). Deaf individuals' bilingual abilities: American Sign Language proficiency, reading skills, and family characteristics. Psychology, 2(01), 18. https://m.scirp.org/papers/3951

[25] Fulcher, A., Purcell, A. A., Baker, E., \& Munro, N. (2012). Listen up: Children with early identified hearing loss achieve age-appropriate speech/language outcomes by 3 years-of-age. International Journal of Pediatric Otorhinolaryngology, 76(12), 1785-1794.

[26] Garberoglio, C. L., Cawthon, S. W., \& Bond, M. (2014). Assessing English literacy as a predictor of postschool outcomes in the lives of deaf individuals. Journal of Deaf Studies and Deaf Education, 19(1), 50-67. https://academic.oup.com/jdsde/article/19/ $1 / 50 / 393984$

[27] Goberis, D., Beams, D., Dalpes, M., Abrisch, A., Baca, R., \& Yoshinaga-Itano, C. (2012). The missing link in language development of deaf and hard of hearing children: Pragmatic language development. Seminars in Speech and Language, 33(04), 297-309.

[28] Golos, D. (2010). Literacy behaviors of deaf preschoolers during video viewing. Sign Language Studies, 11(1), 76-99.
[29] Golos, D. B., \& Moses, A. M. (2013). Developing preschool deaf children's language and literacy learning from an educational media series. American Annals of the Deaf, 158(4), 411-425.

[30] Golos, D. B., \& Moses, A. M. (2015). Supplementing an educational video series with video-related classroom activities and materials. Sign Language Studies, 15(2), 103-125.

[31] Golos, D. B., Moses, A. M., Roemen, B. R., \& Cregan, G. E. (2018). Cultural and Linguistic Role Models. Sign Language Studies, 19(1), 40-74.

[32] Gough, P. B., \& Tunmer, W. E. (1986). Decoding, reading, and reading disability. Remedial and Special Education, 7(1), 610.

[33] Griffin, C. L. (2011). Invitation to public speaking. Cengage Learning.

[34] Guardino, C. (2015). Evaluating teachers' preparedness to work with students who are deaf and hard of hearing with disabilities. American Annals of the Deaf, 160(4), 415-426.

[35] Guardino, C. A. (2008). Identification and placement for deaf students with multiple disabilities: Choosing the path less followed. American Annals of the Deaf, 153(1), 55-64.

[36] Guardino, C., \& Cannon, J. E. (2015). Theory, research, and practice for students who are deaf and hard of hearing with disabilities: Addressing the challenges from birth to postsecondary education. American Annals of the Deaf, 160(4), 347-355.

[37] Harley, T. A. (2013). The psychology of language: From data to theory. Psychology press.

[38] Harris, M., Terlektsi, E., \& Kyle, F. E. (2017). Concurrent and longitudinal predictors of reading for deaf and hearing children in primary school. The Journal of 
Deaf Studies and Deaf Education, 22(2), 233-242.

https://www.ncbi.nlm.nih.gov/pubmed/284 26889

[39] Herman, R., Roy, P., \& Kyle, E. (2014). Reading, dyslexia and oral deaf children: From research to practice.

[40] Hermans, D., Knoors, H., Ormel, E., \& Verhoeven, L. (2008). The relationship between the reading and signing skills of deaf children in bilingual education programs. Journal of Deaf Studies and Deaf Education, 13(4), 518-530.

[41] Higgins, M., \& Lieberman, A. M. (2016). Deaf students as a linguistic and cultural minority: Shifting perspectives and implications for teaching and learning. Journal of Education, 196(1), 9-18.

[42] Hintermair, M. (2015). The Role of Language in Deaf and Hard-of-Hearing Children's. Oxford University Press.

[43] Hrastinski, I., \& Wilbur, R. B. (2016). Academic achievement of deaf and hardof-hearing students in an ASL/English bilingual program. Journal of Deaf Studies and Deaf Education, 21(2), 156-170. https://www.ncbi.nlm.nih.gov/pmc/articles /PMC4886322/

[44] Hulme, C., \& Snowling, M. J. (2014). The interface between spoken and written language: Developmental disorders. Philosophical Transactions of the Royal Society B: Biological Sciences, 369(1634), 20120395.

https://www.ncbi.nlm.nih.gov/pubmed/243 24239

[45] Kilpatrick, J. R. (2015). Developing a written language inventory for deaf and hard of hearing students: A Systemic Functional Grammar approach.

[46] Kirby, J. R. (2007). Reading comprehension: Its nature and development. Encyclopedia of Language and Literacy Development, 1-8.
[47] Knight, P. \& Swanwick, R. (1999) The Care and Education of A Dead Child: A Book for Parents. Clevedon: Multilingual Matters Ltd.

[48] Klatter-Folmer, J., van Hout, R., Kolen, E., \& Verhoeven, L. (2006). Language development in deaf children's interactions with deaf and hearing adults: A Dutch longitudinal study. Journal of Deaf Studies and Deaf Education, 11(2), 238-251.

[49] Kress, G. (2005). Before writing: Rethinking the paths to literacy. Routledge.

[50] Kushalnagar, P., Mathur, G., Moreland, C. J., Napoli, D. J., Osterling, W., Padden, C., \& Rathmann, C. (2010). Infants and children with hearing loss need early language access. The Journal of Clinical Ethics, 21(2), 143.

[51] Kyle, F. E., \& Cain, K. (2015). A comparison of deaf and hearing children's reading comprehension profiles. Topics in Language Disorders, 35(2), 144-156.

[52] Kyle, F. E., Campbell, R., Mohammed, T., Coleman, M., \& MacSweeney, M. (2013). Speechreading development in deaf and hearing children: Introducing the test of child speechreading. Journal of Speech, Language, and Hearing Research.

[53] Lederberg, A. R., Schick, B., \& Spencer, P. (2013). Language and literacy development of deaf and hard-of-hearing children:Successes and challenges. Developmental Psychology,49(1), 15.

[54] Lee, Y., Jeong, S.-W., \& Kim, L.-S. (2013). AAC intervention using a VOCA for deaf children with multiple disabilities who received cochlear implantation. International Journal of Pediatric Otorhinolaryngology, 77(12), 2008-2013.

[55] Leigh, G., \& Johnston, T. (2004). First language learning in a sign bilingual 
program: An Australian study. First Language, 9(2/3).

[56] Levickis, P., Sciberras, E., McKean, C., Conway, L., Pezic, A., Mensah, F. K., Bavin, E. L., Bretherton, L., Eadie, P., \& Prior, M. (2018). Language and socialemotional and behavioural wellbeing from 4 to 7 years: A community-based study. European Child \& Adolescent Psychiatry, 27(7), 849-859. https://www.ncbi.nlm.nih.gov/pubmed/291 43155

[57] Luckner, J. L., \& Cooke, C. (2010). A summary of the vocabulary research with students who are deaf or hard of hearing. American Annals of the Deaf, 155(1), 3867.

[58] Luckner, J. L., \& Handley, C. M. (2008). A summary of the reading comprehension research undertaken with students who are deaf or hard of hearing. American Annals of the Deaf, 153(1), 6-36. https://www.ncbi.nlm.nih.gov/pubmed/186 19066

[59] Luckner, J. L., \& Urbach, J. (2012). Reading fluency and students who are deaf or hard of hearing: Synthesis of the research. Communication Disorders Quarterly, 33(4), 230-241.

[60] MacSweeney, Mairead, Campbell, R., Calvert, G. A., McGuire, P. K., David, A. S., Suckling, J., Andrew, C., Woll, B., \& Brammer, M. J. (2001). Dispersed activation in the left temporal cortex for speech-reading in congenitally deaf people. Proceedings of the Royal Society of London. Series B: Biological Sciences, 268(1466), 451-457.

[61] MacSweeney, Mairéad, Woll, B., Campbell, R., McGuire, P. K., David, A. S., Williams, S. C., Suckling, J., Calvert, G. A., \& Brammer, M. J. (2002). Neural systems underlying British Sign Language and audio-visual English processing in native users. Brain, 125(7), 1583-1593.

[62] Marschark, Mar, \& Maye, T. S. (1998). Interactions of language and memory in deaf children and adults. Scandinavian Journal of Psychology, 39(3), 145-148.

[63] Marschark, Marc. (1997). Psychological development of deaf children. Oxford University Press on Demand.

[64] Marschark, Marc, \& Harris, M. (1996). Success and failure in learning to read: The special case of deaf children. Reading Comprehension Difficulties: Processes and Intervention, 12, 279-300.

[65] Marschark, Marc, \& Hauser, P. C.(2008). Deaf cognition: Foundations and outcomes. Oxford University Press.

[66] Marschark, Marc, Lang, H. G., \& Albertini, J. A. (2001). Educating deaf students: From research to practice. Oxford University Press.

[67] Marschark, Marc, \& Spencer, P. E. (2010). The Oxford handbook of deaf studies, language, and education (Vol. 2). Oxford University Press.

[68] Mathews, E. S. (2017). Language, power, and resistance: Mainstreaming deaf education. Gallaudet University Press.

[69] Mayer, C. (2007). What really matters in the early literacy development of deaf children. The Journal of Deaf Studies and Deaf Education, 12(4), 411-431.

[70] McCreery, R. W., Walker, E. A., Spratford, M., Oleson, J., Bentler, R., Holte, L., \& Roush, P. (2015). Speech recognition and parent-ratings from auditory development questionnaires in children who are hard of hearing. Ear and Hearing, 36(0 1), 60S.

[71] Mitchell, R. E., \& Karchmer, M. (2004). Chasing the mythical ten percent: Parental hearing status of deaf and hard of hearing students in the United States. Sign Language Studies, 4(2), 138-163. 
[72] Moeller, M. P., McCleary, E., Putman, C., Tyler-Krings, A., Hoover, B., \& Stelmachowicz, P. (2010). Longitudinal development of phonology and morphology in children with lateidentified mild-moderate sensorineural hearing loss. Ear and Hearing, 31(5), 625.

[73] Moores, D. F. (2001). Educating the deaf: Psychology, principles, and practices.

[74] Moores, D. F., \& Miller, M. S. (2009). Deaf people around the world: Educational and social perspectives. Gallaudet University Press.

[75] Morgenstern, A., Caët, S., CollombelLeroy, M., Limousin, F., \& Blondel, M. (2010). From gesture to sign and from gesture to word: Pointing in deaf and hearing children. Gesture, 10(2-3), 172$202 . \quad$ https://halshs.archivesouvertes.fr/halshs-00637782/document

[76] Myers, C., Clark, M. D., Musyoka, M. M., Anderson, M. L., Gilbert, G. L., Agyen, S., \& Hauser, P. C. (2010). Black deaf individuals' reading skills: Influence of ASL, culture, family characteristics, reading experience, and education. American Annals of the Deaf, 155(4), 449-457.

https://www.ncbi.nlm.nih.gov/pubmed/213 05979

[77] Nicholas, J. G., \& Geers, A. E. (2006). Effects of early auditory experience on the spoken language of deaf children at 3 years of age. Ear and Hearing, 27(3), 286.

[78] Noble, K. G., Norman, M. F., \& Farah, M. J. (2005). Neurocognitive correlates of socioeconomic status in kindergarten children. Developmental Science, 8(1), 74-87.

[79] Paul, P. (1998) Literacy and deafness: the development of reading, writing and literate thought. Boston: Allyn and Bacon.

[80] Paul, P. (2003) Processes and components of reading. In M. Marschark \& P. E.
Spencer (Eds.), Oxford handbook of deaf studies, language, and education (pp. 97109). New York: Oxford University Press.

[81] Paul, P. V. (2009). Language and deafness. Jones \& Bartlett Learning.

[82] Penna, L. M., Lemos, S. M. A., \& Alves, C. R. L. (2015). Auditory and language skills of children using hearing aids. Brazilian Journal of Otorhinolaryngology, 81(2), 148-157.

[83] Pichler, D. C., \& Koulidobrova, H. (2015). Acquisition of sign language as a second language (L2). The Oxford Handbook of Deaf Studies in Language, 218-230.

[84] Pizzo, L. (2018). Vocabulary instruction for the development of American sign language in young deaf children: An investigation into teacher knowledge and practice. Sign Language Studies, 18(2), 238-265.

[85] Powers, A. R., \& Wilgus, S. (1983). Linguistic complexity in the written language of hearing-impaired children. The Volta Review 85, 201-210.

[86] Quigley, S. P., \& King, C. M. (1980). An invited article: Syntactic performance of hearing impaired and normal hearing individuals. Applied Psycholinguistics, 1(4),329-356.

[87] Ramdhani, A., Ramdhani, M. A., \& Amin, A. S.(2014). Writing a Literature Review Research Paper: A step-by-step approach. International Journal of Basic and Applied Science,3(1),47-56.

[88] Robbins, A. M., Green, J. E., \& Waltzman, S. B. (2004). Bilingual oral language proficiency in children with cochlear implants. Archives of OtolaryngologyHead \& Neck Surgery, 130(5), 644-647. https://www.ncbi.nlm.nih.gov/pubmed/151 48191

[89] Schirmer, B. R., \& McGough, S. M. (2005). Teaching reading to children who are deaf: Do the conclusions of the 
National Reading Panel apply? Review of Educational Research, 75(1), 83-117. https://journals.sagepub.com/doi/abs/10.31 02/00346543075001083

[90] Shojaei, E., Jafari, Z., \& Gholami, M. (2016). Effect of early intervention on language development in hearing-impaired children. Iranian Journal of Otorhinolaryngology, 28(84), 13.

[91] Spencer, P. E., \& Harris, M. (2006). Patterns and effects of language input to deaf infants and toddlers from deaf and hearing mothers. Advances in the Sign Language Development of Deaf Children, 71-101.

[92] Strassman, B. K. (1997). Metacognition and reading in children who are deaf: A review of the research. Journal of Deaf Studies and Deaf Education, 140-149.

[93] Strassman, B. K., \& Schirmer, B. (2013). Teaching writing to deaf students: Does research offer evidence for practice? Remedial and Special Education, 34(3), 166-179.

[94] Swanwick, R. (2002). Sign bilingual deaf children's approaches to writing: Individual strategies for bridging the gap between BSL and written English. Deafness \& Education International, 4(2), 65-83.

https://www.tandfonline.com/doi/abs/10.1 179/146431502790560917

[95] Teschendorf, M., Arweiler-Harbeck, D., \& Bagus, H. (2010). Speech development after cochlear implantation in children with bilingual parents. Cochlear Implants International, 11(sup1), 386-389. https://www.ncbi.nlm.nih.gov/pubmed/211 78802

[96] Thomas, E., El-Kashlan, H., \& Zwolan, T. A. (2008). Children with cochlear implants who live in monolingual and bilingual homes. Otology \& Neurotology, 29(2), 230-234.
[97] Tomblin, J. B., Oleson, J. J., Ambrose, S E., Walker, E., \& Moeller, M. P. (2014). The influence of hearing aids on the speech and language development of children with hearing loss. JAMA Otolaryngology-Head \& Neck Surgery, 140(5), 403-409.

[98] Tomblin, J. B., Walker, E. A., McCreery, R. W., Arenas, R. M., Harrison, M., \& Moeller, M. P. (2015). Outcomes of children with hearing loss: Data collection and methods. Ear and Hearing, 36(0 1), $14 \mathrm{~S}$.

https://www.ncbi.nlm.nih.gov/pmc/articles /PMC4704117/

[99] Traxler, M. J., Corina, D. P., Morford, J. P., Hafer, S., Hoversten, L. J., \& Learning (2014). Deaf readers' response to syntactic complexity: Evidence from self-paced reading. Memory \& Cognition, 42(1), 97111.

[100] Trussell, J. W., \& Easterbrooks, S. R. (2017). Morphological knowledge and students who are deaf or hard-of-hearing: A review of the literature. Communication Disorders Quarterly, 38(2), 67-77. https://journals.sagepub.com/doi/abs/10.11 77/1525740116644889

[101] Tur-Kaspa, H., \& Dromi, E. (2001). Grammatical deviations in the spoken and written language of Hebrew-speaking children with hearing impairments. Language, Speech, and Hearing Services in Schools.

[102] Twitchell, P., Morford, J. P., \& Hauser, P. C. (2015). Effects of SES on literacy development of deaf signing bilinguals. American Annals of the Deaf, 159(5), 433-446.

[103] Volterra, V., \& Bates, E. (1989). Selective impairment of italian grammatical morphology in the congenially deaf: A case study. Cognitive Neuropsychology, 6(3), 273-308. 
[104] Wearmouth, J., Gosling, A., Beams, J., \& Davydaitis, S. (2017). Understanding Special Educational Needs and Disability in the Early Years: Principles and Perspectives. Routledge.

[105] Webster, A. (2017). Deafness, development and literacy. Routledge.

[106] Williams, C., \& Mayer, C. (2015). Writing in young deaf children. Review of Educational Research, 85(4), 630-666. https://journals.sagepub.com/doi/10.3102/ 0034654314564882

[107] Wolbers, K. A., Dostal, H. M., \& Bowers, L. M. (2012). "I was born full deaf." Written language outcomes after 1 year of strategic and interactive writing instruction. Journal of Deaf Studies and Deaf Education, 17(1), 19-38.

[108] Yoshinaga-Itano, C., \& Downey, D. M. (1996). The Psychoeducational Characteristics of School-Aged Students in Colorado with Educationally Significant Hearing Losses. Volta Review, 98(1), 6596.

[109] Yoshinaga-Itano, C., \& Snyder, L. (1985). Form and meaning in the written language of hearing-impaired children. The Volta Review. 